\title{
Growth patterns and masses of the heads and necks of male and female giraffes
}

\author{
G. Mitchell ${ }^{1,2}$, D. Roberts ${ }^{2}$, S. van Sittert $^{2}$, J.D. Skinner ${ }^{2 *}$. \\ Department of Zoology and Physiology, University of Wyoming, USA ${ }^{1}$, and Centre for Veterinary Wildlife \\ Studies, University of Pretoria, South Africa². \\ *Deceased 28 August 2011
}

\begin{abstract}
We have analyzed the growth patterns of the head and neck of 65 male and 71 female giraffes from two different populations of giraffes, and also the dimensions of 19 different components of the head and neck in 8 female and 13 male giraffes, to establish if they showed sexual dimorphism and if sexual selection for a weapon was a possible origin of the long neck of giraffes. We found that in both genders the rate of increase in head mass was hypoallometric with respect to body mass. The rate of increase in neck length was similar in both genders and faster than the rate of increase in body mass. Increases in neck mass tend to be isometric relative to increases in body mass in both genders before puberty ( $\mathrm{ca} 650 \mathrm{~kg}$ body mass in males and $700 \mathrm{~kg}$ in females) but in giraffes of greater body mass increases in neck mass are iso- to hyperallometric in both genders, with final neck, body and head mass being greater in males. The only significant gender difference we found for the dimensions of the 19 different head and neck components was that ossicones and skulls were heavier in mature males than in mature females, but increases in skull mass did not alter the growth pattern of head mass significantly. These data suggest that the morphology and growth patterns of the heads and necks of male and female giraffes are similar, that sexual dimorphism of the head and neck is minimal and can be attributed to secretion of sex steroids. We have concluded that there is no evidence that sexual selection was a factor in the evolution of giraffe morphology and that the long neck of giraffes did not evolve as a weapon
\end{abstract}


in males. The more likely selective advantage of a long neck was improvement of access to high level browse.

Key words. Giraffe, sexual dimorphism, sexual selection, browsing hypothesis

\section{Introduction}

There are two main hypotheses for the origin of the long necks of giraffes. The first is that long necks are the product of co-evolution of giraffe and their forage, principally Acacia species browse (Darwin, 1888; Pellew, 1983a; Cameron \& du Toit, 2007). The second hypothesis is that long necks are the product of sexual selection in males for a weapon (Simmons \& Scheepers, 1996). Long necks may also have evolved because of a mixture of these two (Simmons \& Altwegg, 2010), and/or because of supplemental pressures such as the improved thermoregulation and vigilance that results from their shape (Brownlee, 1963).

Long necks in many taxa have evolved to enable access to more food (Wilkinson \& Ruxton, 2011), and throughout the evolution of Giraffa sp it has been assumed that access to high level browse has been a prominent selection pressure for tallness. But doubt has been cast on the browsing hypothesis by studies that show that giraffe rarely use their necks at full extension to acquire browse and often feed at heights that other browsers do (du Toit, 1990). They also prefer to feed at shoulder height (Young\& Isbell, 1991) most of the time (Leuthold \& Leuthold, 1972), and sometimes graze (Seeber et al, 2012). Moreover browse free from competition from other browsers could be achieved by a neck two metres long rather than the 5 metres that neck length can reach in male and female giraffes, and there is a vigilance cost to feeding at high level (Cameron \& Du Toit, 2005). 
Doubt has been cast on the sexual selection hypothesis by analysis of the allometry of the growth of neck and leg length, and head and neck mass in a population of Zimbabwean giraffes (G.c. giraffa) (Mitchell, van Sittert \& Skinner, 2009). This analysis found that there were few gender differences and those that existed could be explained as generic male/female differences: most mammalian males have final body dimensions greater than their females. These findings differed from those of Simmons \& Scheepers (1996) who studied a population of Namibian giraffes (G.c. capensis). They did not measure neck length and used neck mass as the proxy for neck size, and found neck mass to be positively allometric only in males and not in females. Moreover, while head and neck mass increased throughout life in males, they plateaued in females. Simmons \& Scheepers (1996) concluded that, because of the sexual dimorphism of the way neck and head mass increased in males, the origin of a long neck was sexual selection in males for long strong necks and heavy heads for use in contests to obtain access to females with the best endowed males winning.

Thus, apart from the dichotomy of opinions regarding the adaptive advantages of a long neck and the selection pressures that might have given rise to it, there is no consensus on the growth patterns of the head and neck. We have attempted in this study to provide additional information that could help resolve these differences. Our null hypotheses were that the Zimbabwean and Namibian population groups so far studied do not have different head and neck growth patterns, and that sexual selection was not a main selection pressure for the evolution of a long neck. 


\section{Method}

\section{Study Design}

The structure of the study was, first, to compare growth patterns of heads and necks between the Namibian and Zimbabwean populations to determine if the reason for the different results and conclusions reported is that the populations differ. Secondly, within each population, we analyzed the growth patterns of heads and necks in males and females to assess if genderrelated differences exist between them. Thirdly, we analyzed the origin of neck and head mass by measuring 19 different components of the head and neck in a subset of 21 Zimbabwean giraffes.

\section{Analysis of the two populations and genders}

We analyzed the possibility of differences between the two populations using the data reported by Simmons and Altwegg (2010) for Namibian giraffes and the data we have accumulated on body, neck and head mass in Zimbabwean giraffes (Mitchell, van Sittert \& Skinner, 2009). The data for head, neck, and body mass in Namibian giraffes were extracted from the discreet data points identifiable in Figures 1 and 2 in Simmons and Altwegg (2010). Comparison of genders within each population was done using our data for 30 male (body mass range $=181-1441 \mathrm{~kg}$ ) and 30 female Zimbabwean giraffes (body mass range $=147$ $1029 \mathrm{~kg}$ ), and for 35 male (body mass range $=343-1324 \mathrm{~kg}$ ) and 41 female Namibian giraffes (body mass range $=211-867 \mathrm{~kg}$ ). 


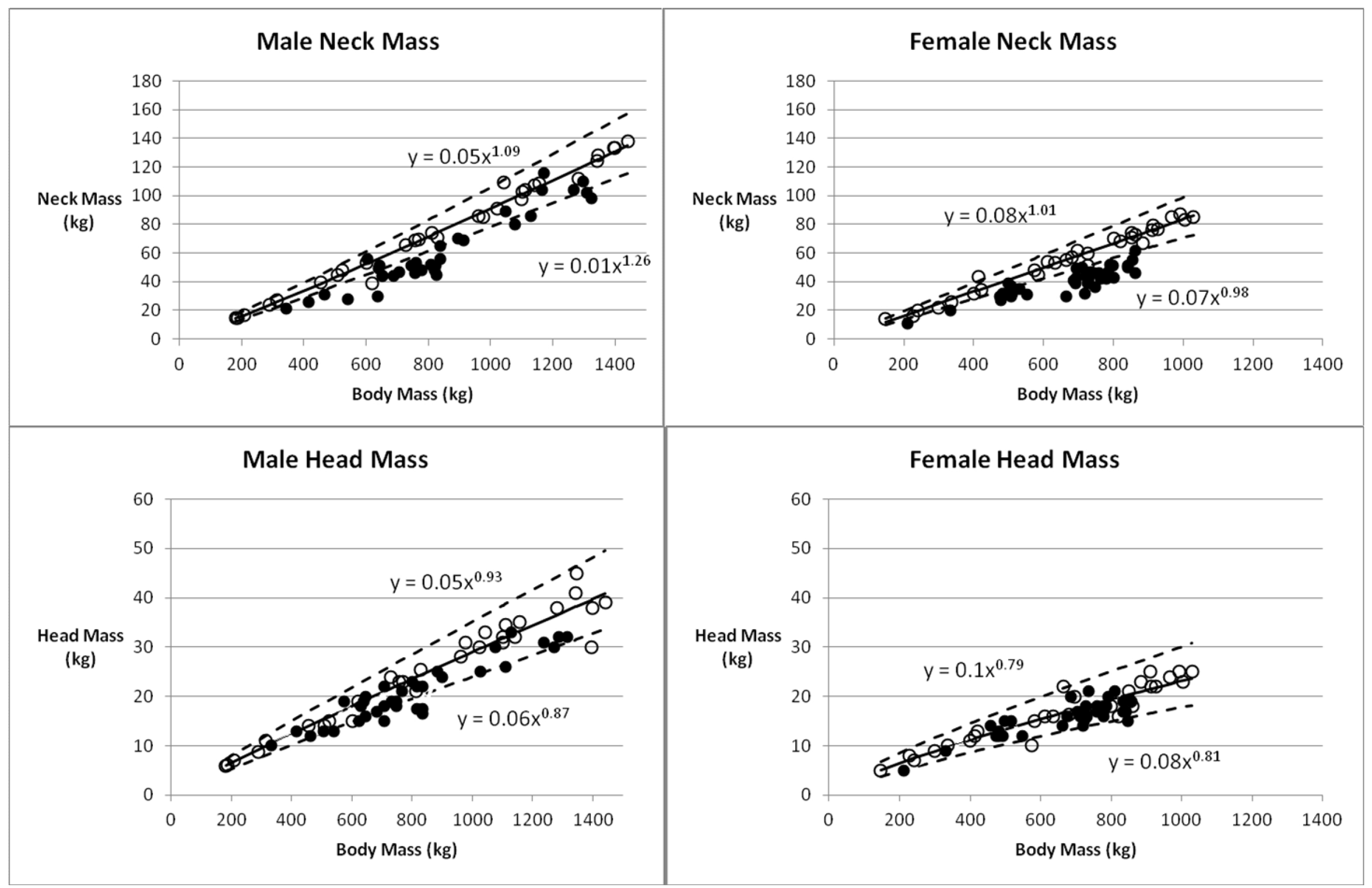

Figure 1 Increase in mass of heads and necks relative to increase in body mass in Zimbabwean (.) and Namibian (•) giraffes. In each graph the dotted lines show the $95 \%$ confidence interval and the solid line the best fit line for Zimbabwean giraffes. Allometric equations on the left describe the growth pattern for Zimbabwean giraffes and those on the right the pattern for Namibian giraffes. The equations show that the growth patterns of the two populations are similar, but compared with Zimbabwean giraffes, absolute neck mass is lower in Namibian giraffes of both genders. 


\section{Analysis of head and neck mass}

We investigated in detail the origin of male and female head and neck masses in a subset of the larger group of Zimbabwean giraffes consisting of 13 male and 8 female giraffes of body mass ranging from $181 \mathrm{~kg}$ to $1396 \mathrm{~kg}$ (males) and $227 \mathrm{~kg}$ to $992 \mathrm{~kg}$ (females).

\section{Body Dimensions}

Body mass $(\mathrm{Mb}, \mathrm{kg})$ of giraffe varies according to season. As some animals were culled in December at the end of the dry season and others in April at the end of summer, their condition varied. Also, a loss of some tissue and fluid occurs during dissection. Therefore, immediately after they were shot, linear dimensions were measured, and the head and neck separated from the body. Remaining body parts, including viscera and skin were weighed in pieces. Body mass was computed from piecemeal body mass and regression equations developed by Hall-Martin (1977) based on measurements of length and girth in metres. These equations are:

Males $(\mathrm{Mb}, \mathrm{kg})=26.117 \cdot \mathrm{L} \cdot \mathrm{G}^{2}+33.945$

Females $(\mathrm{Mb}, \mathrm{kg})=25.400 \cdot \mathrm{L} \cdot \mathrm{G}^{2}+66.109$

Both $(M b, k g)=25.902 \cdot L \cdot G^{2}+45.758$

where $\mathrm{L}$ is total length (see below) and $\mathrm{G}(\mathrm{m})$ the girth of the thorax measured immediately caudal to the front legs. Total length $(\mathrm{L}, \mathrm{m})$ was determined by summing each of the following lengths a) the tip of the nose to the occipital crest (=head length), b) the occipital crest to the highest point of the withers, c) the withers to the base of the tail, and d) the base of the tail to the tip of the tail, following Hall-Martin (1977). 


\section{Neck components}

Eight characteristics of the neck were measured. These were neck mass, neck length, neck circumference at the base, neck circumference at the apex, neck surface area, neck skin mass, cervical vertebrae mass, and, by subtraction, other tissue mass (which is mainly muscle). Neck mass $(\mathrm{kg})$. The neck was weighed after removal of the head and separation from the trunk by a cut running between the seventh cervical and first thoracic vertebrae.

Neck length $(m)$ was measured as the mean of the distances from the occipital crest to the withers and from the angle of the jaw to the point of the shoulder (tuberculum supraglenoidale).

Neck Skin Mass $(\mathrm{kg})$ and Neck Surface Area $\left(\mathrm{m}^{2}\right)$. Prior to dissection of each giraffe the circumference of the neck immediately rostral to the shoulders (base) and immediately caudal to the angle of the jaw (apex) was measured. After the neck had been skinned, the skin was weighed. Neck skin has the shape of a trapezium and its surface area was calculated using the circumference of the base and apex of the neck as the lengths of the parallel sides and neck length as the distance between them.

Cervical Vertebrae Mass ( $\mathrm{kg}$ ). All soft tissue was removed from the skeletons of the giraffes by a combination of dissection and boiling. The mass of each of the seven cervical vertebrae was measured after the vertebrae had been allowed to dry for two days.

\section{Head Components}

Head length was measured in situ. After separation from the neck at the atlanto-occipital joint the mass of the head was measured. Thereafter, soft tissue (skin, eyes, salivary glands, masseter muscles, tongue, brain) were removed by dissection, and the head boiled to remove 
remaining tissue. The skull consisting of the ossicones, the parietal, frontal, temporal, occipital, and maxilla bones, and the bones surrounding the orbit), was weighed before and after removal of the ossicones and separately from the mandible.

\section{Data analysis}

\section{Growth patterns in Namibian and Zimbabwean giraffes}

We investigated growth patterns by developing allometric equations of the form $y=a^{*} M^{b}$, where $a$ is the intercept, $M$ body mass in $\mathrm{kg}$, and $b$ the slope. Intercepts and slopes for the allometric equations and their $95 \%$ confidence limits were determined using the two variable geometric regression calculator available at www.benchmarkcalculations.com., which also generates trend curves for the relationship between covariates and calculates the correlation coefficient $\left(\mathrm{R}^{2}\right)$. We interpreted an increase in neck/head mass as hyperallometric if their rate of increase was on average greater than the rate of increase in body mass (i.e. the exponent was $>1$ ), isometric if the exponent was not significantly different from 1, and hypoallometric if it was $<1$.

\section{Head and Neck Components}

Whether differences in head and neck mass existed between animals in the two populations and whether differences in the components of the head and neck existed between genders was analyzed by determining relative values for each variable by dividing the measurement obtained for each component by a common denominator, usually kg body mass. As the rate of growth of body parts changes over time, we have used the average relative values over the life of the animal to assess differences. Differences were evaluated using the two-sample ttest assuming unequal variances. $\mathrm{P}$ values $<0.05$ were regarded as significant. 


\section{Results}

\section{Analysis of the two populations}

\section{Growth patterns of the head and neck}

Table $1.95 \%$ Confidence Intervals of the exponents for the rate of increase of neck and head mass in Namibian and Zimbabwean giraffes

\begin{tabular}{|c|c|c|c|c|}
\hline Giraffe Type & Exponent Neck & 95\% CI (Neck) & Exponent Head & 95\% CI (Head) \\
\hline Namibian Males & 1.26 & $1.11-1.42$ & 0.87 & $0.75-1.00$ \\
\hline Namibian Females & 0.98 & $0.85-1.12$ & 0.81 & $0.67-0.95$ \\
\hline $\begin{array}{c}\text { Zimbabwean } \\
\text { Males }\end{array}$ & 1.09 & $1.04-1.12$ & 0.93 & $0.87-0.98$ \\
\hline $\begin{array}{c}\text { Zimbabwean } \\
\text { Females }\end{array}$ & 1.01 & $0.95-1.05$ & 0.79 & $0.70-0.88$ \\
\hline
\end{tabular}

The growth patterns of the head and neck in the two population groups are shown in Figure 1 and the 95\% Confidence Intervals (CI) for the exponents in Table 1. In each case the growth pattern and its 95\% confidence limits for Zimbabwean giraffe were the benchmarks on which the data for Namibian giraffes were superimposed. Figure 1 shows that in both genders in both populations growth of head mass was hypoallometric, and most of the data points for Namibian giraffes lie within the $95 \%$ confidence limits for the increase in head mass of Zimbabwean giraffes. In males in both populations increases in neck mass were on average hyperallometric and in females could not be differentiated from isometric. In both genders the data points for Namibian giraffes tend to fall outside the $95 \%$ confidence limits for Zimbabwean giraffes. Comparison of the relative mass of the necks ( $\mathrm{g} / \mathrm{kg}$ body mass) confirmed that the neck mass of male Namibian giraffes $(70.8 \pm 11.6 \mathrm{~g} / \mathrm{kg}$; mean \pm s.d $)$ was significantly lower than it was in the Zimbabwean giraffes $(89.0 \pm 7.2 \mathrm{~g} / \mathrm{kg} ; \mathrm{P}<.05)$. Similarly in female Namibian giraffe relative neck mass $(60.3 \pm 7.1 \mathrm{~g} / \mathrm{kg})$ was significantly lower than it was in Zimbabwean giraffes $(83.3 \pm 6.7 \mathrm{~g} / \mathrm{kg} ; \mathrm{P}<.05)$. 
To compare the growth patterns in males and females in each population, the growth pattern for male giraffes and its $95 \%$ confidence limits were used as the benchmarks on which data points for females were superimposed (Fig. 2). In all four comparisons the female data falls within the $95 \%$ confidence limits of the male data. This finding suggests that up to a body mass of $c a 1000 \mathrm{~kg}$ (the mature body mass of females) the rate of increase in mass of heads and necks in both genders is not significantly different and that neck and head mass in males and females of equivalent body mass are similar. Final body, neck and head masses are higher in males than in females (Fig 2). Because the exponents for neck and head growth patterns in each of the two populations and in each gender are so similar (Table 1), we combined the data from the two populations to produce equations for the growth patterns of heads and necks in male and female giraffes over their lifetimes and equations to show generic growth patterns for head and neck mass in giraffes. These equations, and the average relative masses of heads and necks, are shown in Table 2.

Table 2. Allometric equations for the growth of heads and necks in giraffes

\begin{tabular}{|c|c|c|}
\hline Variable & Allometric Equation & $\begin{array}{l}\text { Relative mass } \\
(\mathrm{g} / \mathrm{kg}: \text { mean } \pm \mathrm{sd})\end{array}$ \\
\hline Male Neck Mass $(\mathrm{kg}) \mathrm{N}=65$ & $\begin{array}{l}.04 * \mathrm{Mb}^{1.10} \\
(95 \% \mathrm{CI}=1.01-1.19) \\
\mathrm{R}^{2}=.9058\end{array}$ & $79.3 \pm 13.4$ \\
\hline Male Head Mass $(\mathrm{kg}) \mathrm{N}=65$ & $\begin{array}{l}.05 * \mathrm{Mb}^{.91} \\
(95 \% \mathrm{CI}=0.85-0.97) \\
\mathrm{R}^{2}=.9268\end{array}$ & $27.9 \pm 3.5$ \\
\hline $\begin{array}{l}\text { Female Neck Mass }(\mathrm{kg}) \\
\mathrm{N}=70\end{array}$ & $\begin{array}{l}.08 * \mathrm{Mb}^{.97} \\
(95 \% \mathrm{CI}=0.85-1.09) \\
\mathrm{R}^{2}=.7972\end{array}$ & $70.2 \pm 13.3$ \\
\hline $\begin{array}{l}\text { Female Head Mass }(\mathrm{kg}) \\
\mathrm{N}=63\end{array}$ & $\begin{array}{l}.09 * \mathrm{Mb}^{.79} \\
(95 \% \mathrm{CI}=0.71-0.87) \\
\mathrm{R}^{2}=.8740\end{array}$ & $24.9 \pm 3.8$ \\
\hline $\begin{array}{l}\text { Generic Neck Mass }(\mathrm{kg}) \\
\mathrm{N}=135\end{array}$ & $\begin{array}{l}.05 * \mathrm{Mb}^{1.07} \\
(95 \% \mathrm{CI}=1.00-1.15) \\
\mathrm{R}^{2}=.8614\end{array}$ & $73.8 \pm 14.0$ \\
\hline $\begin{array}{l}\text { Generic Head Mass }(\mathrm{kg}) \\
\mathrm{N}=128\end{array}$ & $\begin{array}{l}.05 * \mathrm{Mb}^{.89} \\
(95 \% \mathrm{CI}=.84-.95) \\
\mathrm{R}^{2}=.8888\end{array}$ & $26.0 \pm 4.1$ \\
\hline
\end{tabular}




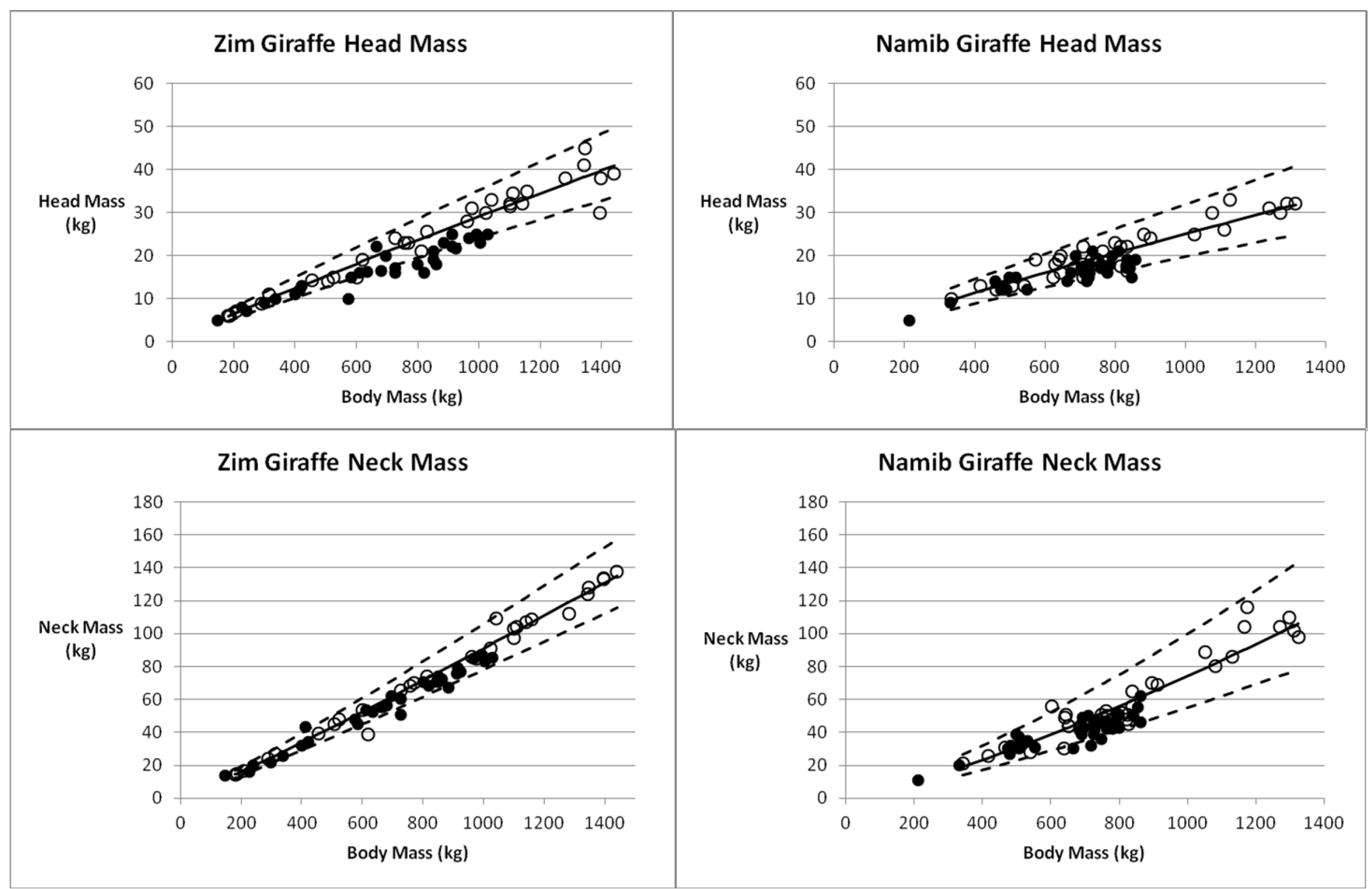

Figure 2 A comparison of the growth rate relative to body mass of heads and necks in male (.) and female $(\bullet)$ Zimbabwean and Namibian giraffes. In each graph, the dotted lines show the $95 \%$ confidence interval for male giraffes, and the solid line is the best fit line for male giraffes. Note that the trajectory of growth does not differ between the genders for either heads or necks, but final body mass is greater in male than in female giraffes. The allometric equations that describe each curve are the same as those shown in Fig. 1. 
We also analyzed whether the growth pattern of the neck changed around puberty. Puberty in male giraffes occurs at 3.3 years of age (Hall-Martin, Skinner, \& Hopkins, 1978) when body mass is ca $650 \mathrm{~kg}$. In females puberty occurs at 3.8 years of age (Hall-Martin \& Skinner, 1978) when body mass is $c a 700 \mathrm{~kg}$. Using these somewhat arbitrary delineators of puberty, we found that in male giraffes of body mass up to $650 \mathrm{~kg}$ and females up to $700 \mathrm{~kg}$ in both Namibian and Zimbabwean giraffes the growth pattern for heads and necks cannot be distinguished from isometry. Beyond these body masses increases in neck mass are on average hyperallometric in both genders and populations, although the large confidence limits suggest that an isometric growth pattern cannot be excluded especially in females (Fig.3 A, B). The rate of increase of head mass tends on average to be iso- to hypoallometric in both genders and both populations before and after puberty (Fig.3 C, D).

\section{Analysis of head and neck masses}

The relative mass of male skulls and ossicones (total skull mass) was heavier than in females (Table 3). This was the only significant gender difference for the components of head mass. The rate of increase in total skull mass relative to increases in body mass was hyperallometric and occurred after puberty (Fig 4A). In the 8 females it was hypoallometric (Fig 4A) and not affected by puberty. The increase in skull mass in males had no effect on the rate of increase of head mass (Fig 4B). The only significant gender difference for the components of the neck was that the relative mass of the seven cervical vertebrae in males was heavier than in females by $1.4 \mathrm{~g} / \mathrm{kg}$ body mass (Table 4 ), but this difference disappeared if males of body mass greater than $1000 \mathrm{~kg}$ were excluded from the sample. 

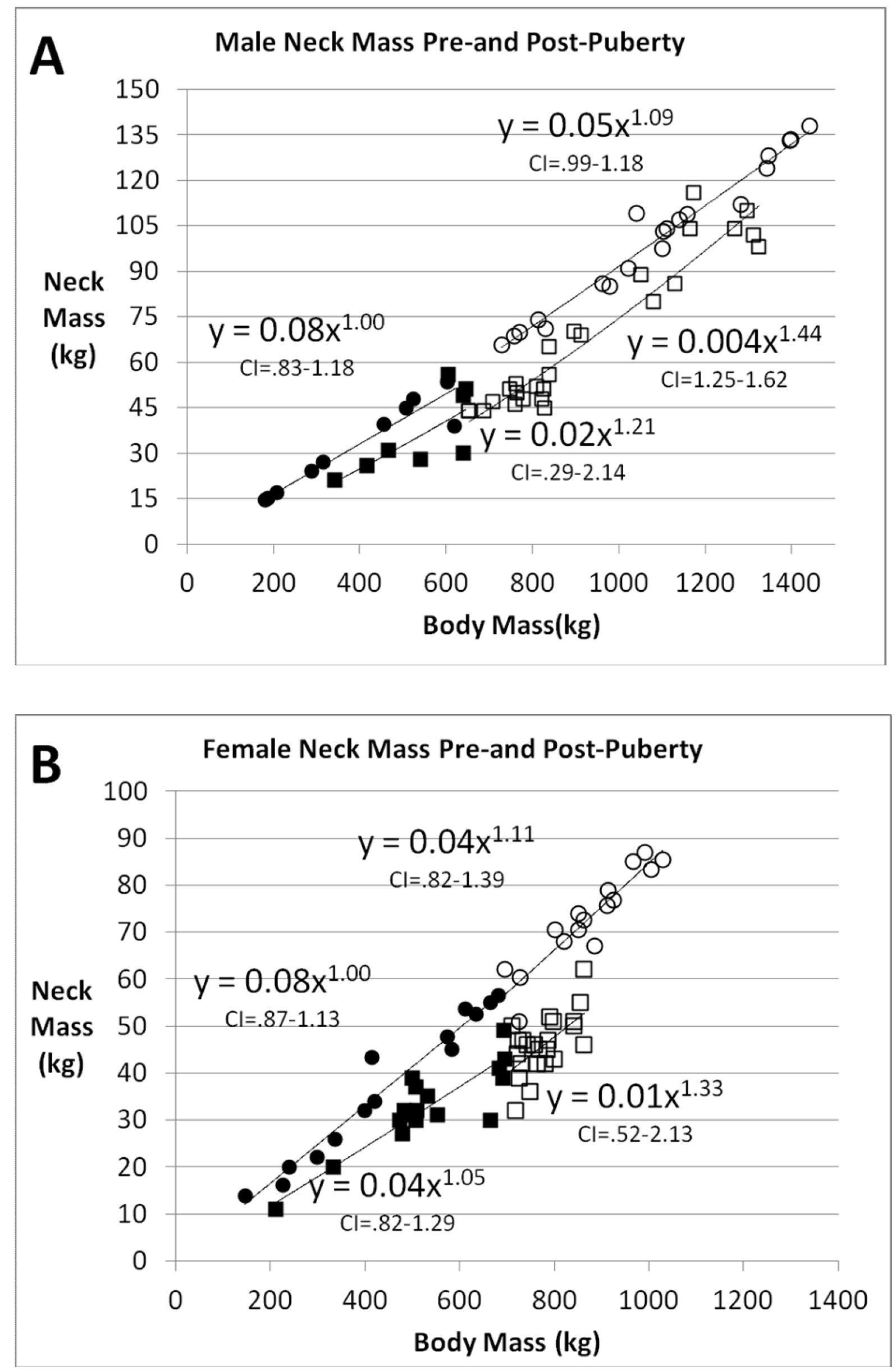

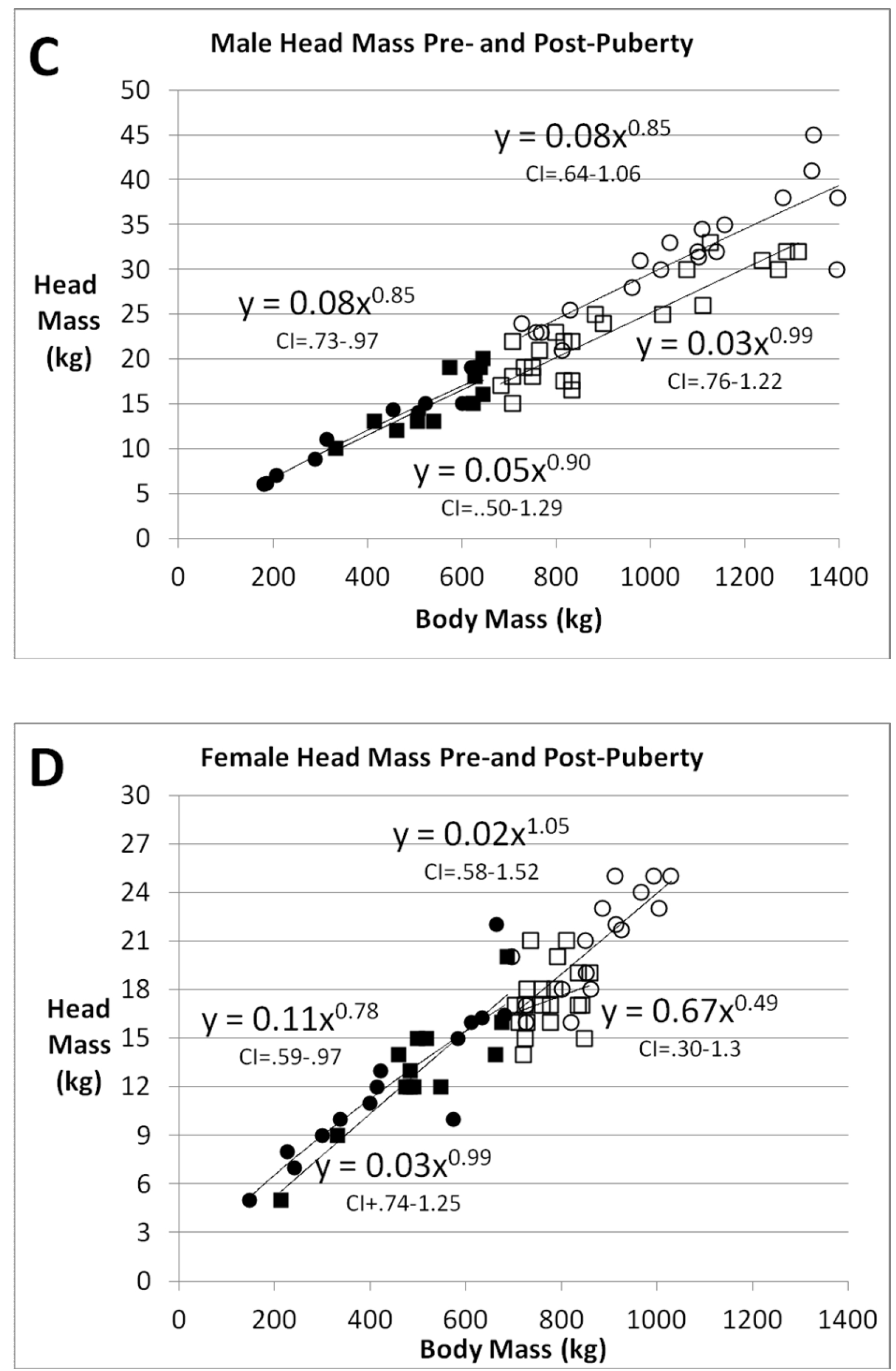

Figure 3 Growth patterns of heads and necks pre- (solid markers) and post- (hollow markers) puberty in Zimbabwean $(\bullet,$.$) and Namibian (., .) giraffes. Equations to the left of the trend lines refer to Zimbabwean and those on the right to$ Namibian giraffes. Note that before puberty $(=650 \mathrm{~kg}$ in male, $700 \mathrm{~kg}$ in female giraffes), growth patterns are very similar. Post-puberty neck mass growth is hyperallometric in both genders and head mass growth iso- or hypoallometric. 

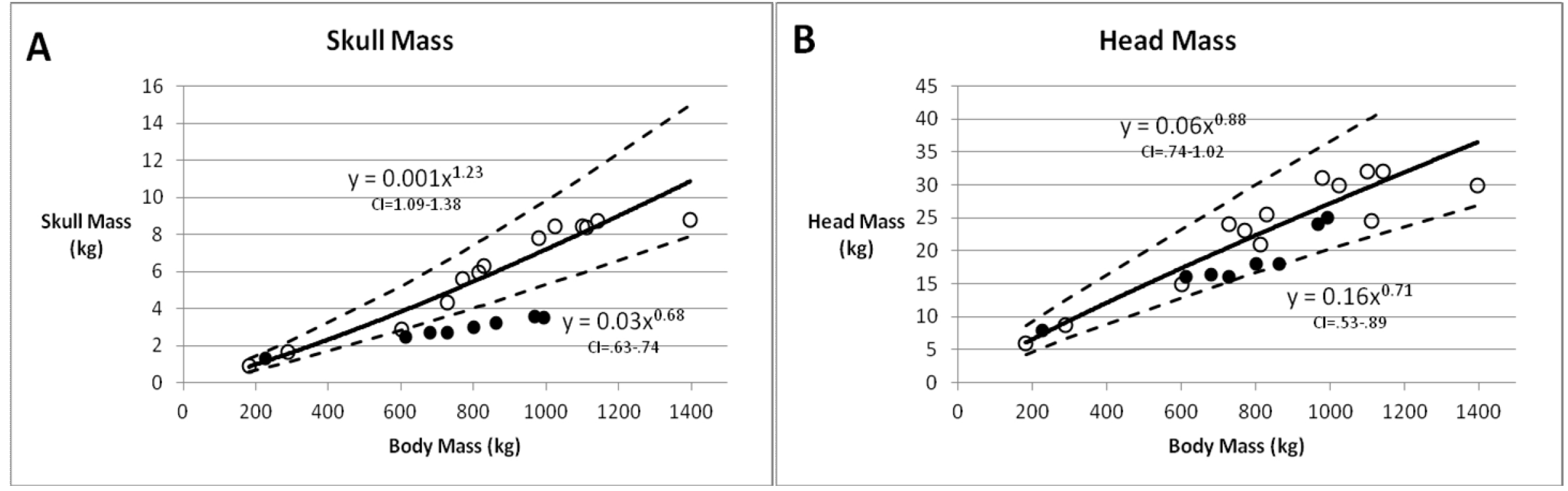

Figure 4 The growth patterns of total skull (ossicones plus skull bone) and head mass in 13 male (.) and 8 female (•) Zimbabwean giraffes. In each graph, the dotted lines are the $95 \% \mathrm{CI}$ and the solid line the best fit line for male giraffes. Allometric equations to the left describe the growth patterns in male and those on the right growth patterns in female giraffes. Note that the increase in male total skull mass is hyperallometric relative to body mass and occurs after puberty $(=$ body mass $650 \mathrm{~kg}$ ), is hypoallometric in female giraffes, and does not affect the growth pattern of head mass significantly, which is similar in both genders. CI $=95 \%$ confidence interval for all the exponents. 
Table 3. Mean \pm standard of relative sizes ( $\mathrm{g} / \mathrm{kg}$ body mass or $\mathrm{cm} / \mathrm{kg}$ body mass) of head length and 11 components of head mass in 13 male and 8 female giraffes.

\begin{tabular}{|c|c|c|c|}
\hline Variable & Male $(\mathrm{N}=13)$ & Female $(\mathrm{N}=8)$ & $\mathrm{P}(\mathrm{t}$-test $)$ \\
\hline Head Mass $(\mathrm{g} / \mathrm{kg})$ & $28.4 \pm 3.8$ & $25.1 \pm 4.4$ & $\begin{array}{c}\mathrm{NS} \\
\mathrm{t}=.1050\end{array}$ \\
\hline $\begin{array}{c}\text { Head Length } \\
(\mathrm{cm} / \mathrm{kg})\end{array}$ & $0.11 \pm 0.05$ & $0.11 \pm 0.04$ & $\begin{array}{c}\mathrm{NS} \\
\mathrm{t}=.8752\end{array}$ \\
\hline $\begin{array}{c}\text { Skull-ossicones } \\
(\mathrm{g} / \mathrm{kg})\end{array}$ & $5.9 \pm 0.9$ & $3.8 \pm 0.6$ & $\mathrm{t}=<.05$ \\
\hline Ossicones $(\mathrm{g} / \mathrm{kg})$ & $0.90 \pm 0.33$ & $0.22 \pm 0.07$ & $\mathrm{t}=<. \mathbf{0 5}$ \\
\hline Total skull $(\mathrm{g} / \mathrm{kg})$ & $6.8 \pm 1.2$ & $4.0 \pm 0.7$ & $\mathrm{t}=<.05$ \\
\hline Mandible $(\mathrm{g} / \mathrm{kg})$ & $1.71 \pm 0.12$ & $1.69 \pm 0.14$ & $\begin{array}{c}\mathrm{NS} \\
\mathrm{t}=.8530\end{array}$ \\
\hline Masseters $(\mathrm{g} / \mathrm{kg})$ & $1.23 \pm 0.22$ & $1.35 \pm 0.31$ & $\begin{array}{c}\mathrm{NS} \\
\mathrm{t}=.3639\end{array}$ \\
\hline Tongue $(\mathrm{g} / \mathrm{kg})$ & $1.58 \pm 0.37$ & $1.59 \pm .31$ & $\begin{array}{c}\mathrm{NS} \\
\mathrm{t}=.9608\end{array}$ \\
\hline Head Skin $(\mathrm{g} / \mathrm{kg})$ & $4.41 \pm 0.78$ & $4.24 \pm 0.92$ & $\begin{array}{c}\mathrm{NS} \\
\mathrm{t}=.6685\end{array}$ \\
\hline Brain $(\mathrm{g} / \mathrm{kg})$ & $0.98 \pm 0.67$ & $1.07 \pm 0.51$ & $\begin{array}{c}\mathrm{NS} \\
\mathrm{t}=.1846\end{array}$ \\
\hline Other Tissue $(\mathrm{g} / \mathrm{kg})$ & $11.7 \pm 3.0$ & $11.2 \pm 2.4$ & $\begin{array}{c}\mathrm{NS} \\
\mathrm{t}=.6578\end{array}$ \\
\hline
\end{tabular}

Table 4. Mean \pm standard of relative sizes ( $\mathrm{g} / \mathrm{kg}$ body mass or $\mathrm{cm} / \mathrm{kg}$ body mass) of 8 neck components in 13 male and 8 female giraffes.

\begin{tabular}{|c|c|c|c|}
\hline Variable & Males $(\mathrm{N}=13)$ & Females $(\mathrm{N}=8)$ & $\mathrm{P}(\mathrm{t}$-test $)$ \\
\hline $\begin{array}{l}\text { Neck length } \\
(\mathrm{cm} / \mathrm{kg})\end{array}$ & $0.24 \pm 0.11$ & $0.24 \pm 0.08$ & $\begin{array}{c}\mathrm{NS} \\
\mathrm{t}=.9687\end{array}$ \\
\hline Neck Mass $(\mathrm{g} / \mathrm{kg})$ & $101.8 \pm 8.6$ & $92.8 \pm 10.0$ & $\begin{array}{c}\mathrm{NS} \\
\mathrm{t}=.0559\end{array}$ \\
\hline $\begin{array}{c}\text { Neck } \\
\text { Circumference } \\
\text { (base) }(\mathrm{cm} / \mathrm{kg})\end{array}$ & $.22 \pm .10$ & $.21 \pm .08$ & $\begin{array}{c}\mathrm{NS} \\
\mathrm{t}=.8165\end{array}$ \\
\hline $\begin{array}{c}\text { Neck } \\
\text { Circumference } \\
\text { (apex) }(\mathrm{cm} / \mathrm{kg})\end{array}$ & $.10 \pm .05$ & $.10 \pm .05$ & $\begin{array}{c}\mathrm{NS} \\
\mathrm{t}=.9367\end{array}$ \\
\hline $\begin{array}{l}\text { Neck Surface area } \\
\left(\mathrm{cm}^{2} / \mathrm{kg}\right)\end{array}$ & $25.1 \pm 4.3$ & $23.2 \pm 3.3$ & $\begin{array}{c}\mathrm{NS} \\
\mathrm{t}=.2702\end{array}$ \\
\hline $\begin{array}{c}\text { Cerv.Vert. Mass } \\
(\mathrm{g} / \mathrm{kg})\end{array}$ & $9.3 \pm 0.1$ & $7.9 \pm 0.15$ & $\mathrm{t}=<.05$ \\
\hline Neck Skin $(\mathrm{g} / \mathrm{kg})$ & $16.8 \pm 1.8$ & $17.6 \pm 2.8$ & $\begin{array}{c}\mathrm{NS} \\
\mathrm{t}=.4461\end{array}$ \\
\hline $\begin{array}{l}\text { Other Neck tissue } \\
\text { (muscle) }(\mathrm{g} / \mathrm{kg})\end{array}$ & $75.8 \pm 7.7$ & $67.3 \pm 10.3$ & $\begin{array}{c}\mathrm{NS} \\
\mathrm{t}=.0684\end{array}$ \\
\hline
\end{tabular}

\section{Discussion}

Darwin (1874) developed the theory of sexual selection to account for the sexual dimorphism shown by secondary sexual characters such as horns, and sexual dimorphism has become a 
criterion for testing sexual selection of a characteristic. The study we report here set out to identify if sexual dimorphism was present in the heads and necks of male and female giraffes and so test, therefore, whether sexual selection is a possible explanation for the evolution of their long neck. In two previous analyses of this possibility opposite conclusions were drawn based on measurements made in two different populations of giraffes, one in Namibia (Simmons \& Scheepers, 1996) and the other in Zimbabwe (Mitchell et al, 2009). The reanalysis we report here of these two populations has led us to conclude that there are no significant differences in growth patterns between the populations or between Namibian and Zimbabwean giraffes except perhaps that Namibian giraffes may be smaller. Therefore, the difference in conclusions drawn in the earlier studies probably lies in the structure of the populations studied, with, as can be seen from Fig 1, the most important difference being that the Zimbabwean group consisted of animals with a wider range of body masses than did the Namibian group, especially amongst the females.

There are two possible origins of sexual dimorphism. One is related to different growth rates and different duration of growth in each gender (Reeve \& Fairbairn, 1996; Badyaev, 2002). These differences result in the development of secondary sexual characters and produce the typical difference in size between male and female mammals (Wright 1993). The other can be attributed to sexual selection for usually a single characteristic that is confined to one of the genders (Badyaev, 2002). Three criteria were used by Simmons \& Scheepers (1996) to establish if a single characteristic, namely neck mass, was unique to male giraffes and therefore evidence for sexual selection. These were positive (hyper-) allometry for neck mass in males, the use by males of their necks to win contests for females, and a survival cost for males of a long neck. 
With respect to the allometry of neck mass, our data suggest that hyperallometric growth of neck mass while usual in males can occur in some females so it does not seem to be an exclusive characteristic of male giraffes: in both Namibian and Zimbabwean giraffes the mass of female necks falls within the $95 \%$ confidence limits of the male data. This result suggests that at least up to a body mass of about 1000kg the growth trajectory of neck mass in both genders is similar, and differences that exist occur because increases in neck mass continue for a longer period in males than in females (Fig 2). Moreover, our data suggest that neck mass itself does not show significant sexual dimorphism: the relative mass of the necks of male and female giraffes is not significantly different (Tables $1 \& 3$ ).

Furthermore, as the head more than the neck, is the weapon in contests then increases in head mass should also show hyperallometry in males if the sexual selection hypothesis is correct. However, increases in head mass are iso- or hypoallometric (Figs.1,2) and the rate of increase in head mass does not change after puberty (Fig.3). In both genders head mass increases throughout life but the rate of increase slows as maturity approaches. It also might be expected that if the neck evolved as a weapon in males then there would not only be sexual dimorphism in neck mass but also in neck length, but there is not. In the subset of 21 giraffes studied we found that the rate of increase in male neck length $(\mathrm{cm})\left(11.2 * \mathrm{Mb}^{.41}(95 \% \mathrm{CI}=\right.$ $\left.0.38-0.44 ; \mathrm{R}^{2}=.9630\right)$ was the same as the rate of increase in females $\left(8.3 * \mathrm{Mb}^{.45}\right.$ $\left(95 \% \mathrm{CI}=0.41-0.50 ; \mathrm{R}^{2}=.9402\right)$, which is the same as we have reported previously (Mitchell et al, 2009).

Increases in total skull mass (skull + ossicones) are, on the other hand, hyperallometric in males and hypoallometric in females (Fig.4) and skulls are significantly heavier in males than they are in females of equivalent body mass (Table 2). Ossicones are heavier in males 
because they increase in length and diameter after puberty. The heavier male skull mass can be attributed to its thicker bones and the development of bony knobs with age (Dagg, 1965; Spinage, 1968). This heavier mass has no effect on the rate of increase in head mass because skull + ossicone mass contributes relatively little to the mass of the head. Of the $28.4 \mathrm{~g} / \mathrm{kg}$ of head mass in males, $21.6 \mathrm{~g} / \mathrm{kg}(76 \%)$ is made up of non-skull tissue. In females $21.1 \mathrm{~g} / \mathrm{kg}$ of $25.1 \mathrm{~g} / \mathrm{kg}(84 \%)$ of head mass is non-skull tissue (Table 2$)$. In all other respects our data show that the growth patterns of the head and neck of male and female giraffes are essentially identical, that the rate of growth of neck mass in both genders and of skull mass in males changes at puberty and that the termination of growth occurs much later in males than in females. These growth patterns are typical of growth in large terrestrial herbivorous mammals and they are regulated by sex steroids (Wright 1993; Reeve \& Fairbairn, 1996; Badyaev, 2002).

A second criterion used by Simmons and Scheepers (1996) was the use of the neck and head by males in contests to gain access to females. However, their use in contests is not confined to large males (Coe, 1960; Pratt \& Anderson, 1982; 1985). In their study of giraffe social behavior made over a period of 10 months and encompassing 3264 hours of observation, Pratt \& Anderson $(1982 ; 1985)$ studied the social interaction of 304 males. They recorded 166 bouts of necking (164 bouts of sparring and only 2 of fighting). In none of these were large mature bulls with the "stoutest necks and largest ossicones" seen to participate. Necking usually occurred between young, immature males, which as our data show, have heads and necks whose proportions are not significantly different to females of equivalent body mass. Access of immature bulls to cows was limited, and necking was practiced by them to establish a dominance hierarchy and not to gain access to cows (Pratt \& Anderson, 1982). Winners of contests did not have the longest and strongest necks. These findings show that 
dominance and neck morphology are not linked, and therefore, necking is very unlikely to have driven sexual selection for a trait such as neck mass.

Darwin (1874) identified a survival cost as a characteristic of a sexually selected trait but on the contrary the structure of the head and neck of giraffes of both genders has survival benefits. Cameron and Du Toit (2007) have confirmed that a long neck is a significant advantage when lower leaves of trees have been eaten by smaller browsers and a long neck gives access to leaves at the centre of low trees and shrubs that are out of reach to smaller browsers. In both genders it gives exclusive access to browse between 2-5 metres high. Browse below this level amounts to $57 \%$ of what is eaten by giraffes. The other $43 \%$ is added by browse above this level (Pellew, 1983a). In effect a long neck doubles the food supply. High level browse contains three times more browse per cubic metre of space than low level browse (Pellew 1983a), it is higher in protein, energy, and minerals that giraffes actively select (Sauer, Skinner, \& Neitz, 1982; Pellew 1984a, 1984b; Mitchell, van Schalkwyk, \& Skinner, 2005), and has more browse per bite (Cameron \& Du Toit, 2007). Consumption of high quality nutrients results in faster growth, a younger age at first conception, shorter calving intervals, shorter generation gaps, more calves per female, and better lactation, all of which are cornerstones of successful survival (Pellew 1983b; 1983c).

Morphological adaptations that have evolved to facilitate feeding at high level are numerous. Apart from co-evolution and co-elongation of long legs and necks over a long period of time (Colbert, 1938; Mitchell \& Skinner, 2003; Wilkinson \& Ruxton, 2011), giraffe have evolved a skull that is enlarged by the presence of sinuses that are far larger relative to cranial mass than observed in other adult artiodactyls (Badlangana et al, 2011). As a result the head mass of giraffes is significantly less than expected from its size. In addition, giraffe necks taper 
markedly from base to apex, which reduces mass cranially: the circumference of the neck at the base (on average $159 \mathrm{~cm}$ in the male giraffes in this study) is more than twice that at the head (on average $70 \mathrm{~cm}$ ). A similar relationship exists for the females in the study group (140 $\mathrm{cm}$ and $63 \mathrm{~cm}$ respectively). The mass of the cervical vertebrae also decreases rostrally (van Schalkwyk, Skinner, \& Mitchell, 2004). Giraffes, therefore, have a combination of a decreasing neck mass with distance along the neck and a much lighter head than predicted. Furthermore, their occipital condyles "are remarkable for their extent in the vertical direction; it is this structure which enables the giraffe to raise the head into a line with the neck, and even to bend it a little way back upon the neck" when it feeds at high level (Owen,1838). They also have an exceptionally well developed ligamentum nuchae, which functions to suspend the head and neck with minimal muscular effort, a modification which first appeared in Giraffokeryx 12 Mya associated with the development of a longer neck (Mitchell \& Skinner, 2003). Unique to giraffes is that the development of the ligament also is associated with a decrease in the size of the dorsal spines of the cervical vertebrae and, therefore, reduced vertebra mass and extensor muscle mass (van Sittert, Skinner \& Mitchell, 2010). All these adaptations facilitate the maneuverability required to feed on high level browse. Finally, we found that the increase in the mass of the masseter muscles in both genders is on average hyperallometric (exponent $\left.=1.23 ; 95 \% \mathrm{CI}=.93-1.32 ; \mathrm{R}^{2}=.8831\right)$ presumably reflecting the effort of browsing.

In summary, the data we report here derived from a re-analysis of two populations of giraffes and a detailed analysis of head and neck components in male and female giraffes, do not support the sexual selection hypothesis for necks needed for "necking" in males. If sexual selection was a factor then it might be expected that head and neck mass and neck length would all show sexual dimorphism. However, increases in neck length, head mass and neck 
mass in both male and female giraffes are essentially identical. Only skull and ossicone mass of mature males differ significantly from those of females. We have concluded, therefore, that the alternative high browse hypothesis is the more likely explanation for tallness in giraffes.

\section{Acknowledgements}

We thank the management and staff of the Bubye Valley Conservancy, Zimbabwe for their logistical support and sponsorship of this study. An anonymous reviewer made many helpful comments. Funds were provided by the Don Craib Trust (JDS), from a personal research grant (JDS) and the University of Wyoming (GM). Technical field support was provided by Carl-Heinz Moeller, Kenneth Manyangadze, Mark Brewer, Lauren Leathem, Kyle Piearse, Declan Gallagher, Blake Wilelmi, Marie Watson and Megan North.

\section{References}

Badlangana, N.L., Adams, J.W., \& Manger, P.R. 2011. A comparative assessment of the size of the frontal air sinuses in the giraffe (Giraffa camelopardalis). Anat. Rec. 294,931940.

Badyaev, A.V. 2002. Growing apart: an ontogenetic perspective on the evolution of sexual size dimorphism. Trends Ecol. Evol. 17, 369-378.

Brownlee, A. 1963. Evolution of the giraffe. Nature 200, 1022.

Cameron, E.Z., \& du Toit, J.T. 2005. Social influences on vigilance behaviour in giraffes, Giraffa camelopardalis. Anim. Behav. 69,1337-1344.

Cameron, E.Z., \& du Toit, J.T. 2007. Winning by a neck: Tall giraffes avoid competing with shorter browsers. Am. Nat. 169(1), 130-135.

Coe, M.J. 1967. "Necking” behaviour in the giraffe. J. Zool. 151,313-321.

Colbert E.H. 1938. The relationships of the okapi. J. Mammal. 19: 47-50.

Dagg, A.I. 1965. Sexual differences in giraffe skulls. Mammalia 29, 610- 612.

Darwin, C.R. 1874. The descent of man and selection in relation to sex. $2^{\text {nd }}$ edn. London: John Murray.

Darwin, C.R. 1888. The origin of species: By means of natural selection, the preservation of favoured 
races in the struggle for life. $6^{\text {th }}$ edn. London: John Murray.

du Toit, J.T. 1990. Feeding-height stratification among African browsing ruminants. Afr. J. Ecol. 28, $55-61$.

Hall-Martin, A.J. 1977. Giraffe weight estimation using dissected leg weight and body measurements. J. Wildlife Manage. 41(4), 740-745.

Hall-Martin, A.J., \& Skinner, J.D. 1978. Observations on puberty and pregnancy in female giraffe (Giraffa camelopardalis). S. Afr. J. Wildl. Res. 8, 91-94.

Hall-Martin, A.J., Skinner, J.D., \& Hopkins, B.J. 1978. The development of the reproductive organs of the male giraffe, Giraffa camelopardalis. J. Reprod.Fertil. 52, 1-7.

Leuthold, B.M., \& Leuthold, W. 1972. Food habits of giraffe in Tsavo National Park, Kenya. East Afr. Wildl. J. 10,129- 141.

Mitchell, G., \& Skinner, J.D. 2003. On the origin, evolution and phylogeny of giraffes Giraffa camelopardalis. T. Roy.Soc. S. Afr. 58(1), 51-73.

Mitchell, G., van Schalkwyk, O.L., \& Skinner, J.D. 2005. The calcium and phosphorus content of giraffe (Giraffa camelopardalis) and buffalo (Syncerus caffer) skeletons. J. Zool. 264, 307-315.

Mitchell, G., van Sittert, S., \& Skinner, J.D. 2009. Sexual selection is not the origin of long necks in giraffes. Journal of Zoology (London). 278:281-286, 2009.

Owen, R. 1838. Notes on the anatomy of the Nubian giraffe. Trans. Zool. Soc. London. 2, 217-248.

Pellew, R.A. 1983a. The impact of elephant, giraffe, and fire upon the Acacia tortillas woodlands of the Serengeti. Afr. J. Ecol. 21, 41-74.

Pellew, R.A. 1983b. The giraffe and its food resource in the Serengeti. I. Composition, biomass, and production of available browse. Afr. J. Ecol. 21,241-267.

Pellew, R.A. 1983c. The giraffe and its food resource in the Serengeti. II. Response of the giraffe population to changes in the food supply. Afr. J. Ecol. 21, 269-283.

Pellew, R.A. 1984a. Food consumption and energy budgets of the giraffe. J. App. Ecol. 21,141-159.

Pellew, R.A. 1984b. The feeding ecology of a selective browser, the giraffe (Giraffa camelopardalis tippelskirchi). J. Zool. 202,57-81.

Pratt, D.M., \& Anderson, V.H. 1982. Population, distribution, and behaviour of giraffe in the Arusha National Park, Tanzania. J. Nat. Hist. 16, 481-489.

Pratt, D.M., \& Anderson, V.H. 1985. Giraffe social behavior. J. Nat. Hist. 19,771-781.

Reeve, J.P., \& Fairbairn, D.J. 1996. Sexual size dimorphism as a correlated response to selection on body size: an empirical test of the quantitative genetic model. Evolution 50, 1927-1938.

Sauer, J.J.C., Skinner, J.D., \& Neitz, A.W.H. 1982. Seasonal utilization of leaves by giraffes, Giraffa camelopardalis, and the relationship of the seasonal utilization to the chemical composition of the leaves. S. Afr. J. Zool. 17, 210-219. 
Seeber, P.A., Ndlovu, H.T., Duncan, P., \& Ganswindt, A. 2012. Grazing behavior of the giraffe in Hwange National Park, Zimbabwe. Afr. J. Ecol. 50, 247-250.

Simmons, R.E., \& Altwegg, R. 2010. Necks-for-sex or competing browsers? A critique of ideas on the evolution of giraffe. J. Zool. 282:6-12

Simmons, R.E., \& Scheepers, L. 1996. Winning by a neck: sexual selection in the evolution of giraffe. Am. Nat. 148(5), 771-786.

Spinage, C.A. 1968. Horns and other bony structures of the skull of the giraffe, and their functional significance. East Afr. Wildl. J. 6, 53-61.

van Schalkwyk, O.L., Skinner, J.D., \& Mitchell, G. 2004. A comparison of the bone density and morphology of giraffe (Giraffa camelopardalis) and buffalo (Syncerus caffer) skeletons. J. Zool. 264,307-315.

van Sittert, S.J., Skinner, J.D., \& Mitchell, G., 2010. From fetus to adult - an allometric analysis of the giraffe vertebral column. J. Exp. Zool. B 314b (6),469-479.

Young, T.P., \& Isbell L.A. 1991. Sex differences in giraffe feeding ecology: energetic and social constraints. Ethology 87, 79-89.

Wilkinson,D.M., \& Ruxton, G.D. 2011. Understanding selection for long necks in different taxa. Biol. Rev. doi: 10.1111/j.1469-185X.2011.00212.x

Wright, D.B. 1993. Evolution of sexually dimorphic characters in peccaries (Mammalia, Tayassuidae). Paleobiology. 19(1),52-70. 